\title{
Reaproveitamento da areia de fundição como material de base e sub-base de pavimentos flexíveis
}

\author{
Luis Miguel Gutiérrez Klinsky¹; Glauco Tulio Pessa Fabbri²
}

\begin{abstract}
Resumo: O principal resíduo das indústrias de fundição é a areia de fundição de descarte que, no ano 2007, no Brasil, ultrapassou os três milhões de toneladas. Com o objetivo de preservar os recursos naturais e diminuir a degradação do meio ambiente, procuram-se alternativas para reutilizar a areia de fundição em grandes quantidades e a utilização na construção de rodovias fornece oportunidades. Assim, este trabalho avaliou a possibilidade de reutilizar a areia de fundição, misturada a solos argilosos, como material de base e subbase para rodovias de baixo volume de tráfego e vias urbanas para a região de Sertãozinho/SP, que é geradora de resíduo de areia de fundição, mas carece de jazidas de solos arenosos para a construção de rodovias. No estudo foi empregada a técnica de estabilização granulométrica para obter misturas solo-areia em diferentes proporções, nas quais foram realizados ensaios de classificação, propriedades mecânicas e ambientais. Os resultados dos ensaios mostraram que solos argilosos com $60 \%$ de areia de fundição adicionada poderiam ser utilizados como material de sub-base e base para pavimentos de tráfego leve, com baixo risco de poluir o meio ambiente.
\end{abstract}

Abstract: The main residue of the foundry industries is the foundry sand that in 2007, in Brazil, exceeded three millions tons. The modern world searches the preservation of the natural resources and the reduction of the environment degeneration. Aiming at these objectives, new alternatives are researched to reuse the foundry sand in large amounts and the pavement construction provides opportunities. This paper evaluated the reuse of the foundry sand in pavement sub-bases and bases, through its incorporation to clay soils from Sertaozinho/SP. This region has a high production of foundry metals and residues, and does not have natural sandy soils deposits for pavement construction. This study used the mechanic stabilization technique to obtain soil-sand mixes and classification tests, mechanical properties tests and environment tests were done in these artificial soils. The results showed that clay soils with the addition of $60 \%$ of foundry sand could be used as sub-base and base material for low traffic pavements, with low risk of environment pollution.

\section{INTRODUÇÃO}

Um dos maiores desafios contemporâneos, em termos ambientais, é a disposição adequada dos resíduos sólidos, principalmente aqueles gerados em indústrias. O propósito é recuperar matéria e energia, de maneira a preservar os recursos naturais e diminuir a degradação do meio ambiente.

A indústria de fundição tem como principal resíduo sólido a areia de fundição de descarte, que nos últimos anos no país experimentou um rápido crescimento, o que tem representado um aumento na demanda de espaço para sua disposição, o que se traduz em custos mais elevados para o setor.

Com a finalidade de reduzir a disposição da areia de fundição em aterros de descarte, universidades e empresas têm desenvolvido pesquisas para encontrar um destino mais adequado para este resíduo. Estas pesquisas estão relacionadas à reutilização da areia fora da atividade de fundição, isto é, aplicando reciclagem secundária. Portanto, procura-se uma alternativa para o reuso da areia de fundição, na qual as quantidades

\footnotetext{
${ }^{1}$ Luis Miguel Gutiérrez Klinsky, Universidade de São Paulo, Escola de Engenharia de São Carlos, Departamento de Transportes, SP, Brasil. (e-mail: chiligk@hotmail.com).

${ }^{2}$ Glauco Tulio Pessa Fabbri, Universidade de São Paulo, Escola de Engenharia de São Carlos, Departamento de Transportes, SP, Brasil. (e-mail: glauco@sc.usp.br).
}

Manuscrito recebido em 7/12/2008 e aprovado para publicação em $1 / 6 / 2009$. Este artigo é parte de TRANSPORTES, volume XVII, número 2, dezembro de 2009. ISSN: 1415-7713. consumidas sejam tais que permitam uma redução substancial da disposição do resíduo e, nesse sentido, a utilização na construção de camadas de base e subbase de rodovias fornece oportunidades para o reuso desses resíduos em grandes quantidades.

Muitas regiões no Brasil apresentam solos argilosos lateríticos que não têm características adequadas para emprego como bases e sub-bases de pavimentos. No entanto, esses solos, quando misturados com areias, podem fornecer materiais com comportamento semelhante ao de um solo arenoso fino laterítico (SAFL).

Assim, o objetivo deste trabalho consiste em avaliar a possibilidade de reutilizar a areia de fundição misturada a solos argilosos da região de Sertãozinho/SP como material para base e sub-base de rodovias de baixo volume de tráfego e vias urbanas, com VDM inferior a 1500 veículos e com $\mathrm{N} \leq 5 \times 10^{6}$ solicitações de eixo padrão de $80 \mathrm{kN}$.

Para atingir o objetivo deste estudo foi necessário recorrer à técnica de estabilização granulométrica de solos em laboratório, a partir de uma matriz de solo à qual foram agregadas quantidades determinadas de areia de fundição. Nas misturas solo-areia resultantes foram realizados ensaios de interesse à engenharia viária, objetivando a obtenção de um material que apresentasse características semelhantes às do SAFL.

\section{REVISÃO BIBLIOGRÁFICA}

A fundição é o processo de produção de peças metálicas que são obtidas vertendo-se um metal ou uma liga 
metálica fundida sobre um molde oco, geralmente feito de areia.

Segundo Siegel et al. (1982), a importância da metodologia utilizada na moldagem no processo de fundição deve-se aos numerosos processos e materiais existentes que são empregados e que influenciam na qualidade dos resíduos. Os processos básicos de fundição podem ser classificados da seguinte maneira: em areia verde, em areia seca, em areia-cimento, em areia de macho, pelo processo $\mathrm{CO}_{2}$, em casca (Shell Molding), pelo processo de cera perdida ou por investimento (Investment Casting), em moldes permanentes e em moldes semi-permanentes.

Os moldes confeccionados com areia aglomerada dão origem a mais de $80 \%$ dos produtos fundidos (Mariotto, 2000). O ligante mais usual é a argila (moldagem em areia verde) para dar forma às superfícies externas do produto fundido. Para a fabricação dos machos são utilizadas areias com resinas sintéticas, que geralmente são de origem fenólica.

As areias de fundição são essencialmente produtos de quartzo, originários da decomposição mecânica pela ação atmosférica; suas propriedades são influenciadas pelo tipo de rocha que as originaram, pela forma de processamento da decomposição, pelo transporte e pelas transformações ocorridas após sedimentação (Berndt, 1989).

Segundo Mariotto (2000), o parque industrial brasileiro de fundição tem cerca de 1000 empresas e o Estado de São Paulo concentra $60 \%$ desse parque. A Tabela 1 apresenta a produção de fundidos no Brasil de 2004 a 2008; segundo a ABIFA; nela se observa o constante crescimento do setor e, portanto, segundo a bibliografia, dos resíduos. Calcula-se que para cada tonelada de metal fundido se tenha aproximadamente uma tonelada de areia de fundição descartada (McIntyre et al., 1992).

Assim, constata-se que o passivo ambiental no país é preocupante e, por esse motivo, as indústrias de fundições têm entre seus objetivos reduzir e/ou dispor os resíduos sólidos da melhor maneira possível, dado que esses resíduos são bem conhecidos (pó, escórias, areias de descarte) e, de certa maneira, encarecem o processo de produção.

A areia de fundição pode ser reutilizada principalmente na área de construção civil. Deste ponto de vista, muitas instituições brasileiras e mundiais têm se preocupado com o desenvolvimento de projetos que possibilitem a reutilização deste resíduo. Alguns desses projetos visam sua reutilização em: concreto, fabricação de tijolos e tubos, terraplenagens para a construção de rodovias; aterros drenantes, misturas asfálticas, pavimentação asfáltica armada, agricultura, etc.

\section{MATERIAIS E MÉTODOS}

A areia de fundição e a areia virgem utilizadas neste trabalho foram coletadas do aterro sanitário da empresa Pama Mecânica e Fundição Ltda., uma das muitas empresas de fundição estabelecidas em Sertãozinho/SP. Essa empresa, de porte médio, usa o processo de moldagem de cura a frio (cold-box), utilizando $98,56 \%$ de areia de quartzo; $1,2 \%$ de resina fenólica e $0,24 \%$ de catalisador ( $20 \%$ do teor da resina), sendo o processo $100 \%$ manual, e descarta aproximadamente $200 \mathrm{t} / \mathrm{mês}$ de areia. A areia utilizada neste trabalho não recebeu nenhum tratamento especial nem destorroamento prévio ao seu emprego em laboratório. A Figura 1 apresenta as curvas granulométricas da areia virgem e da areia de fundição.

Tabela 1. Produção de fundidos no Brasil (ABIFA, 2009)

\begin{tabular}{lccccc}
\hline \multirow{2}{*}{ Mês } & \multicolumn{5}{c}{ Produção } \\
\cline { 2 - 6 } & $\mathbf{2 0 0 4}$ & $\mathbf{2 0 0 5}$ & $\mathbf{2 0 0 6}$ & $\mathbf{2 0 0 7}$ & $\mathbf{2 0 0 8}$ \\
\hline Janeiro & 178.828 & 225.938 & 240.463 & 232.256 & 263.989 \\
\hline Fevereiro & 217.382 & 236.174 & 251.657 & 245.896 & 289.204 \\
\hline Março & 238.388 & 257.018 & 282.928 & 282.954 & 291.125 \\
\hline Abril & 227.689 & 242.023 & 251.291 & 264.495 & 302.229 \\
\hline Maio & 240.629 & 252.702 & 280.169 & 286.388 & 303.205 \\
\hline Junho & 246.969 & 257.164 & 271.366 & 273.573 & 302.640 \\
\hline Julho & 249.854 & 248.937 & 268.585 & 277.424 & 315.358 \\
\hline Agosto & 254.496 & 267.225 & 279.589 & 300.671 & 299.930 \\
\hline Setembro & 249.313 & 254.356 & 250.968 & 275.074 & 304.777 \\
\hline Outubro & 250.561 & 248.293 & 252.175 & 291.450 & 305.578 \\
\hline Novembro & 249.072 & 251.682 & 258.148 & 287.814 & 239.760 \\
\hline Dezembro & 266.735 & 227.113 & 199.706 & 231.578 & 137.437 \\
\hline TOTAL & $\mathbf{2 . 8 2 9 . 9 1 6}$ & $\mathbf{2 . 9 6 8 . 6 2 5}$ & $\mathbf{3 . 0 8 7 . 0 4 5}$ & $\mathbf{3 . 2 4 9 . 5 7 3}$ & $\mathbf{3 . 3 5 5 . 2 3 2}$ \\
\hline
\end{tabular}




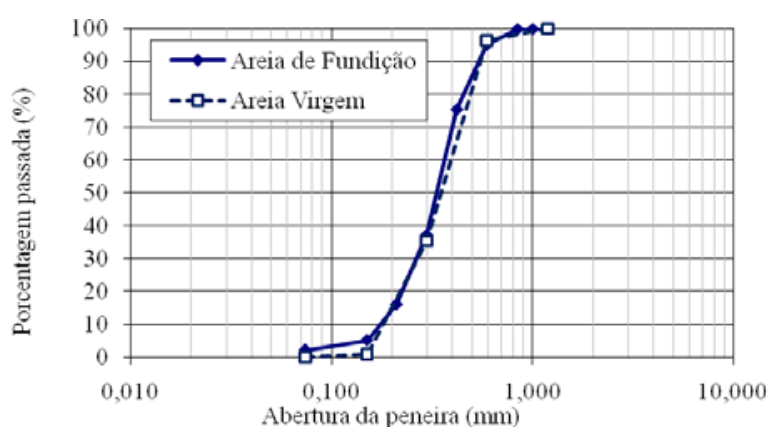

Figura 1. Distribuições granulométricas das areias virgens e de fundição utilizadas na empresa Pama Mecânica e Fundição Ltda

Os solos argilosos também foram coletados na região de Sertãozinho/SP, nos bairros Jardim Botânico (JB) e Nova Aliança (NV). A Tabela 2 apresenta as principais características dos solos coletados e a Figura 2 mostra as suas distribuições granulométricas.

Tabela 2. Produção de fundidos no Brasil (ABIFA, 2009)

\begin{tabular}{llcc}
\hline \multicolumn{1}{c}{ Solo } & & $\begin{array}{c}\text { Jardim Botânico } \\
(\text { JB })\end{array}$ & $\begin{array}{c}\text { Nova Aliança } \\
\text { (NA) }\end{array}$ \\
\hline Limite de liquidez & $(\%)$ & 47 & 47 \\
\hline Limite de plasticidade & $(\%)$ & 31 & 28 \\
\hline Índice de plasticidade & $(\%)$ & 16 & 19 \\
\hline Passante \#4 & $(\%)$ & 100 & 100 \\
\hline Passante \#10 & $(\%)$ & 100 & 100 \\
\hline Passante \#40 & $(\%)$ & 98 & 99 \\
\hline Passante \#200 & $(\%)$ & 95 & A-7-6 \\
\hline Classificação HRB & & A-7-5 & CL \\
\hline Classificação USCS & & ML & \\
\hline
\end{tabular}

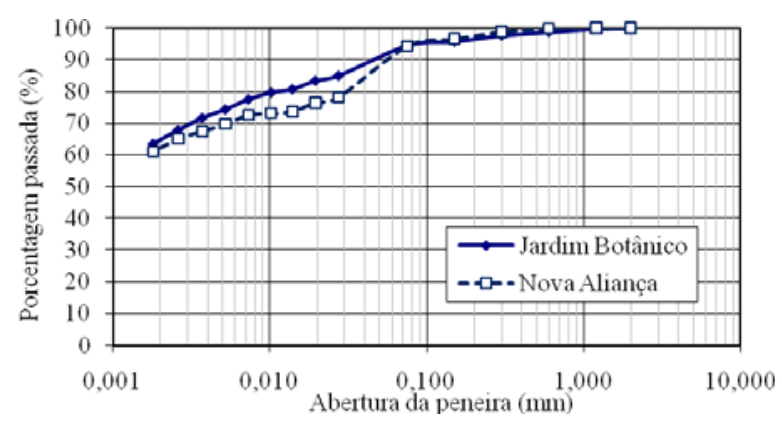

Figura 2. Distribuições granulométricas dos solos Jardim Botânico e Nova Aliança

A técnica utilizada neste estudo foi a de estabilização granulométrica; para isso, o solo Jardim Botânico (JB) foi misturado com areia de fundição (AF) em diferentes teores, em peso $(0 \%, 20 \%, 40 \%, 60 \%, 70 \%)$. Nessas misturas de solo-areia resultantes foram executados ensaios de classificação HRB, USCS e MCT para obter previsão do comportamento dos solos. Também foram executados ensaios de interesse à pavimentação, tais como: CBR, expansão, mini-CBR e associ- ados e triaxial cíclico. Finalmente, com o propósito de determinar o potencial de periculosidade do resíduo, foram executados ensaios ambientais.

A partir da avaliação dos resultados dos ensaios citados anteriormente, obtidos para a matriz Jardim Botânico foi determinada uma porcentagem de areia adicionada ao solo que foi denominada de "Teor Ótimo de Areia de Fundição" por apresentar propriedades mecânicas adequadas para sua utilização em bases e sub-bases de pavimentos urbanos e rodoviários de baixo volume de tráfego.

Para efeito de comparação, adotou-se o valor do "Teor Ótimo de Areia de Fundição" para testar o solo Jardim Botânico (JB) misturado com Areia Virgem (AV) com o propósito de avaliar a influencia do processo de fundição sobre a areia empregada. De forma similar, o solo Nova Aliança (NV) foi misturado à Areia de Fundição (AF) e à Areia Virgem (AV) no nesse mesmo "Teor Ótimo".

\section{RESULTADOS}

\subsection{Classificação das misturas solo-areia}

A Figura 3 apresenta as distribuições granulométricas das misturas solo-areia para os diferentes teores de areia de fundição utilizados e a Figura 4 mostra as classificações obtidas na metodologia MCT.

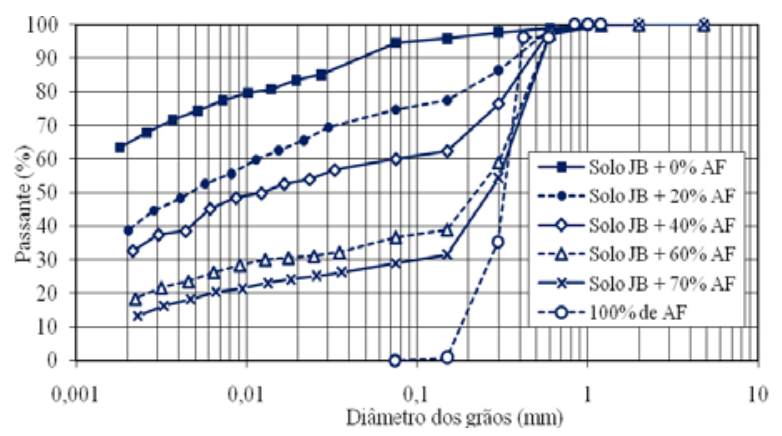

Figura 3. Distribuições granulométricas das misturas para o solo matriz Jardim Botânico

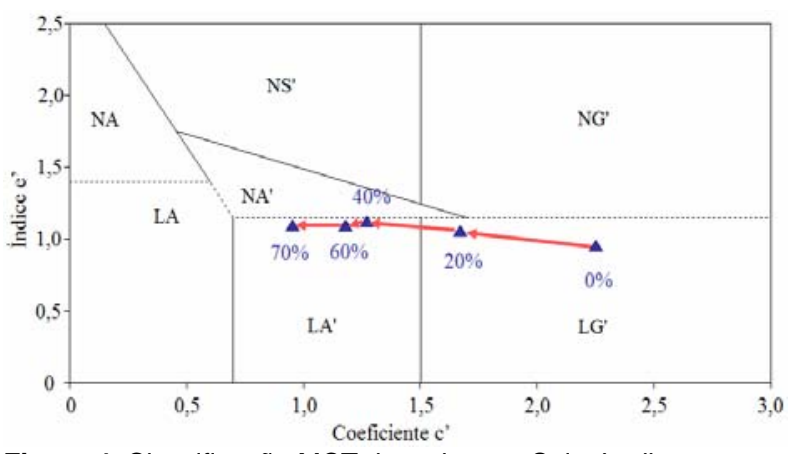

Figura 4. Classificação MCT das misturas Solo Jardim Botânico - Areia de fundição

A Tabela 3 apresenta um resumo das propriedades avaliadas nas misturas solo-areia que permitem suas classificações pelos sistemas tradicionais HRB e 
Tabela 3. Resumo das classificações HRB, USCS e MCT para a matriz Jardim Botânico

\begin{tabular}{lcccccc}
\hline & & Solo “JB" & $\mathbf{2 0 \%}$ & $\mathbf{4 0 \%}$ & $\mathbf{6 0 \%}$ & $\mathbf{7 0 \%}$ \\
\hline Limite de liquidez & $(\%)$ & 47 & 40 & 32 & 27 & 23 \\
\hline Limite de plasticidade & $(\%)$ & 31 & 24 & 20 & 19 & 15 \\
\hline Índice de plasticidade & $(\%)$ & 16 & 16 & 12 & 8 & 8 \\
\hline Passante \#4 & $(\%)$ & 100 & 100 & 100 & 100 & 100 \\
\hline Passante \#10 & $(\%)$ & 100 & 100 & 100 & 100 & 100 \\
\hline Passante \#40 & $(\%)$ & 98 & 93 & 90 & 85 & 84 \\
\hline Passante \#200 & $(\%)$ & 95 & 75 & 60 & 37 & 29 \\
\hline MEAS & $\left(\mathrm{g} / \mathrm{cm}^{3}\right)$ & 3,124 & 2,964 & 2,812 & 2,782 & 2,724 \\
\hline c' & & 2,25 & 1,66 & 1,27 & 1,18 & 0,96 \\
\hline e' & & 0,95 & 1,04 & 1,11 & 1,10 & 1,08 \\
\hline Classificação HRB & & A-7-5 & A-6 & A-6 & A-4 & A-2-4 \\
Classificação USCS & & ML & CL & CL & SM-SC & SM-SC \\
Classificação MCT & & LG' & LG' & LA' & LA' & LA' \\
\hline
\end{tabular}

USCS e pela metodologia MCT. Cabe ressaltar que, embora as classificações tenham sido desenvolvidas para materiais naturais, se usadas para as misturas deste trabalho, poderiam indicar ou fornecer uma previsão do seu comportamento para sua utilização em pavimentos. Assim, a partir das classificações tradicionais, pode se verificar que os solos SM e SC e A-4 e A-2-4 apresentam previsão de comportamento de regular a bom como material de subleito. Para a classificação MCT, os solos com 0 e $20 \%$ de areia apresentaram comportamento Laterítico Argiloso (LG'), indicando uso, preferencial, como proteção à erosão; entretanto, os solos com adição de 40 a $70 \%$ de areia apresentam comportamento Laterítico Arenoso (LA'), material ideal para ser usado em bases e sub-bases de pavimentos, reforços de subleitos e aterros (Nogami e Villibor, 1995).

\subsection{Ensaio mini-CBR}

A execução do ensaio de mini-CBR é importante já que possibilita o dimensionamento de pavimentos e a escolha de solos para reforço do subleito, sub-bases, bases e acostamentos, (Villibor et al. 2007). A variação do valor do mini-CBR imediato, em função do teor de areia de fundição adicionado ao solo Jardim Botânico é apresentado na Figura 5; nela verifica-se que não houve um aumento significativo desse índice de suporte em função do aumento da porcentagem de areia. Por outro lado, o mini-CBR após 24 horas de imersão aumentou, mas sem apresentar uma tendência constante (ver Figura 5). Entretanto, constata-se que foram obtidos, para $60 \%$ de areia adicionada, valores de $52 \%$ para o mini-CBR imediato e $48 \%$ após $24 \mathrm{~h}$ de imersão.

Do ensaio de mini-CBR foram obtidos também os valores de umidade ótima, massa específica seca má- xima, contração, expansão e perda de suporte por imersão das misturas solo-areia. A Figura 6a mostra a tendência decrescente da umidade ótima, conforme aumenta o teor de resíduo de areia de fundição adicionado ao solo Jardim Botânico. Na Figura 6b são apresentados os valores das massas específicas secas máximas, onde se constata o seu aumento com o incremento do teor de areia.

$\mathrm{Na}$ Figura 7a observa-se que os valores de expansão, obtidos do ensaio de mini-CBR, são inferiores a $0,3 \%$, valor máximo permitido para uso em bases de pavimentos; já os valores de contração variam de 0,2 a $1,7 \%$, sendo admissíveis, para uso em pavimentos, as misturas com teores de 60 a $70 \%$ de areia de fundição, por apresentarem contrações inferiores a $0,5 \%$ (DERSP, 2005, ET-DE-P00-015A). A Figura 7b mostra os valores de perda de suporte por imersão; nela é verificado que todos os solos apresentam perdas de suporte inferiores a $50 \%$, sendo que os solos com 20, 40 e $60 \%$ de areia adicionada têm as menores perdas (inferiores a $10 \%)$.

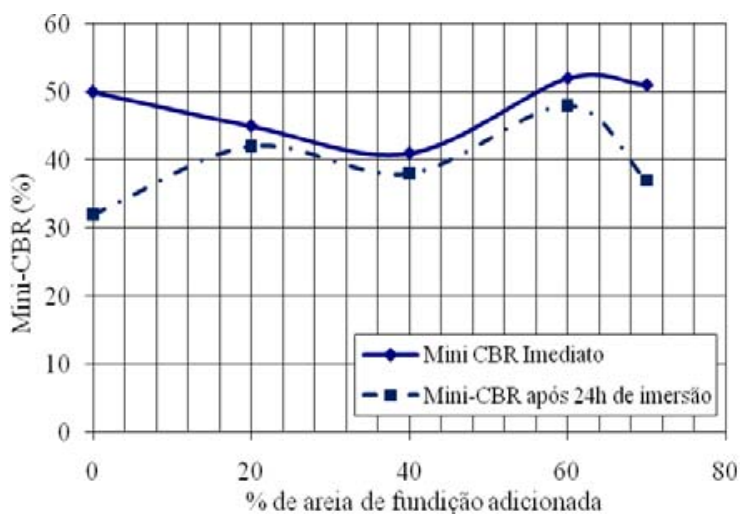

Figura 5. Variação do mini-CBR imediato e após $24 \mathrm{~h}$ de imersão em função do teor de areia de fundição adicionado 


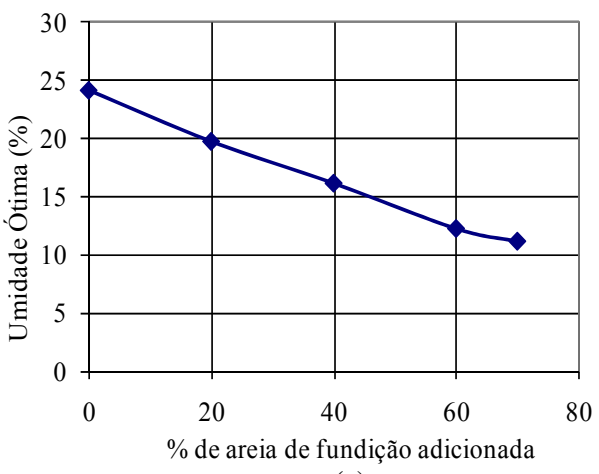

(a)

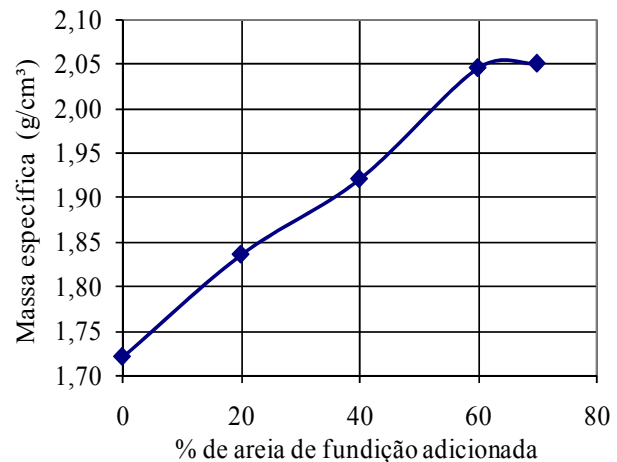

(b)

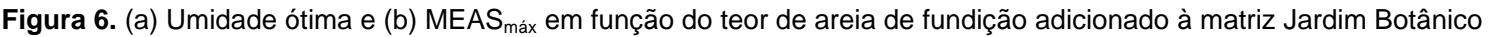

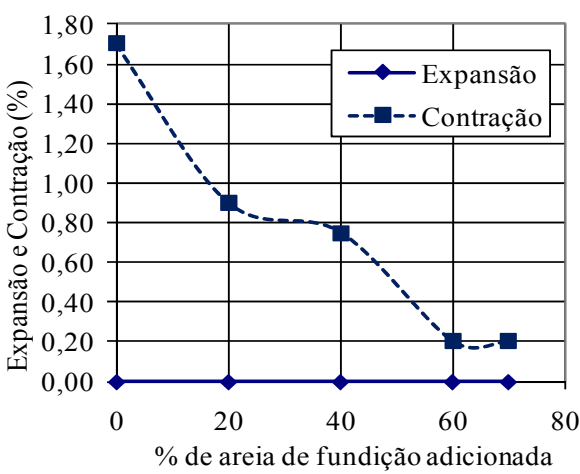

(a)

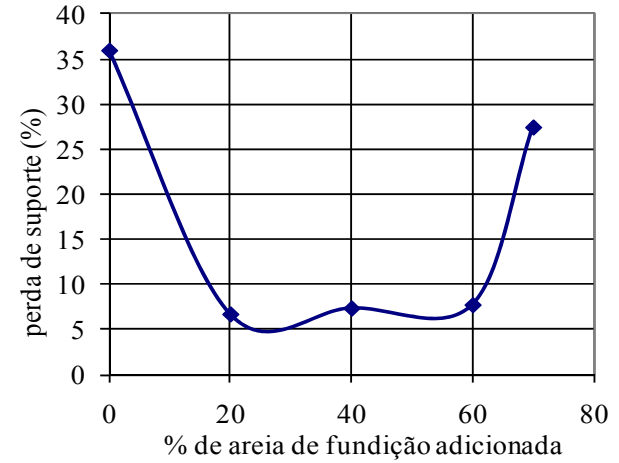

(b)

Figura 7. (a) Expansão e Contração e (b) Perda de suporte em função do teor de areia de fundição adicionado à matriz Jardim Botânico

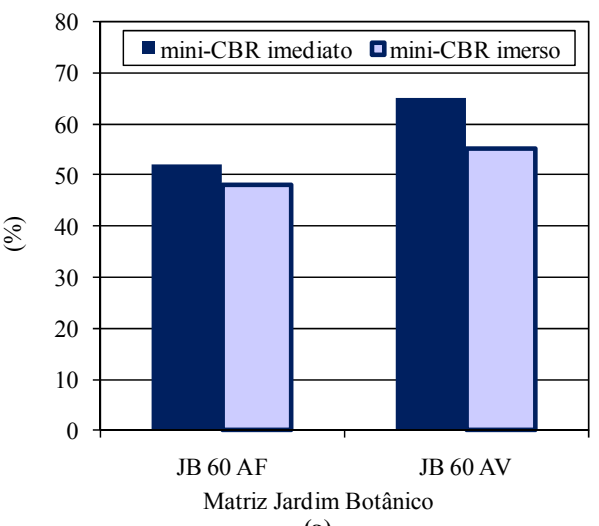

(a)

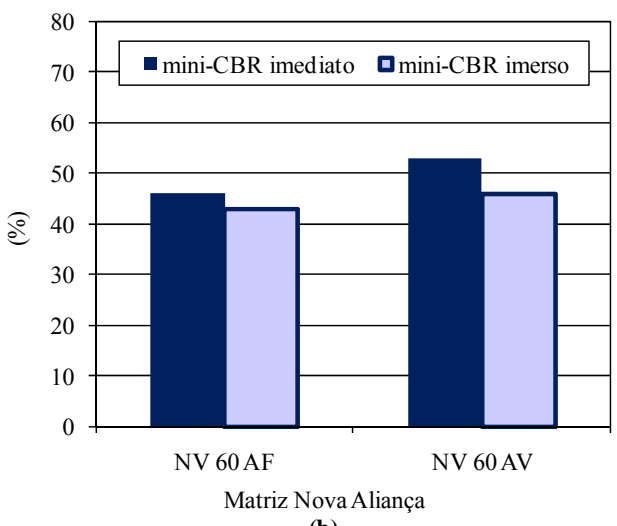

(b)

Figura 8. Mini-CBR imediato e após imersão para as matrizes Jardim Botânico e Nova Aliança, misturadas com areia de fundição e areia virgem, no teor de $60 \%$

O teor de areia de fundição adicionado ao solo Jardim Botânico igual a $60 \%$ foi o que apresentou propriedades satisfatórias, do ponto de vista de sua aplicação em bases e sub-bases de pavimentos. Baseado nesse teor foram montadas misturas solo-areia utilizando-se a Areia de Fundição (AF) e a Areia Virgem (AV) e os solos Jardim Botânico (JB) e Nova Aliança (NV).

As Figuras $8 \mathrm{a}$ e $8 \mathrm{~b}$ mostram que os valores de miniCBR imediato e após imersão são maiores para os solos com Areia Virgem (AV), quando comparado aos valores obtidos nos solos montados a partir da adição de Areia de Fundição, tanto para a matriz Jardim Botânico quanto para a matriz Nova Aliança. Esse aumento pode ser atribuído ao desgaste e eventual arre- dondamento que a areia sofre no processo de moldagem de metais, no qual determinadas propriedades de superfície podem ter sido modificadas ao entrar em contato com os metais fundidos.

\subsection{Infiltrabilidade e Permeabilidade das misturas solo-areia}

A infiltrabilidade (sorção) e a permeabilidade têm sido pouco consideradas em estudos geotécnicos tradicionais para obras viárias e de pavimentação (Nogami \& Villibor, 1995); com objetivo de analisar a influência da areia adicionada ao solo nestas propriedades, foram feitos ensaios da metodologia MCT complementares para determinar os coeficientes de infiltrabilidade e de permeabilidade. 

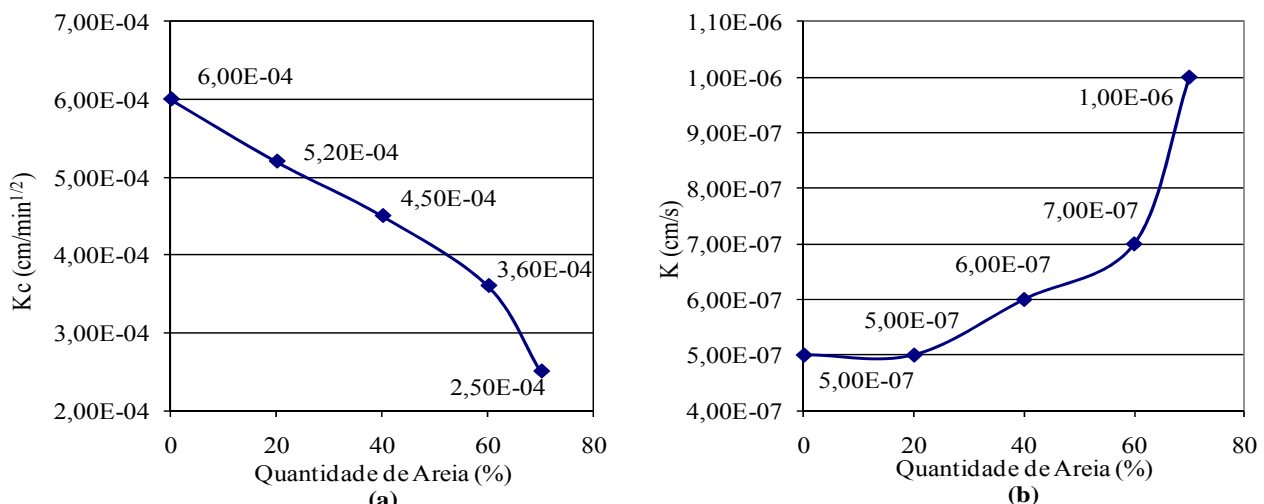

Figura 9. Coeficientes de Sorção $(\mathrm{Kc})$ e Permeabilidade $(\mathrm{K})$ versus a porcentagem de areia de fundição adicionada à matriz Jardim Botânico

A Figura 9a mostra a tendência decrescente do coeficiente de sorção $(\mathrm{Kc})$ com o aumento do teor de areia de fundição adicionada ao solo. O solo Jardim Botânico puro apresenta um coeficiente de sorção igual a $6,0 \times 10^{-4} \mathrm{~cm} / \mathrm{min}^{1 / 2} \mathrm{e}$, para o mesmo solo com $70 \%$ de areia adicionada, o coeficiente decresce até o valor de $2,5 \times 10^{-4} \mathrm{~cm} / \mathrm{min}^{1 / 2}$. Tal comportamento é coerente segundo Nogami \&Villibor (1995), que afirmam que os solos lateríticos argilosos apresentam coeficientes de sorção maiores que os dos solos lateríticos arenosos.

Na Figura 9b são apresentados os valores dos coeficientes de permeabilidade (K). Nela nota-se que o solo JB puro tem um coeficiente de permeabilidade igual a $5,0 \times 10^{-7} \mathrm{~cm} / \mathrm{s}$ e com a adição de areia ele aumenta até o valor de $1,0 \times 10^{-6} \mathrm{~cm} / \mathrm{s}$. Apesar desse aumento, pode se observar que o solo com $70 \%$ de areia - maior porcentagem adicionada ao solo - ainda apresenta um valor baixo de permeabilidade, influenciado pelo o alto teor de argila do solo utilizado na mistura, o que garante a impermeabilidade dos solos "montados" mesmo com teores de areia expressivos.

Observa-se ainda na Figura 9b que o coeficiente de permeabilidade apresenta uma tendência crescente com o aumento do teor de areia de fundição adicionada ao solo do Jardim Botânico. Esta tendência crescente era esperada, já que solos com mais partículas

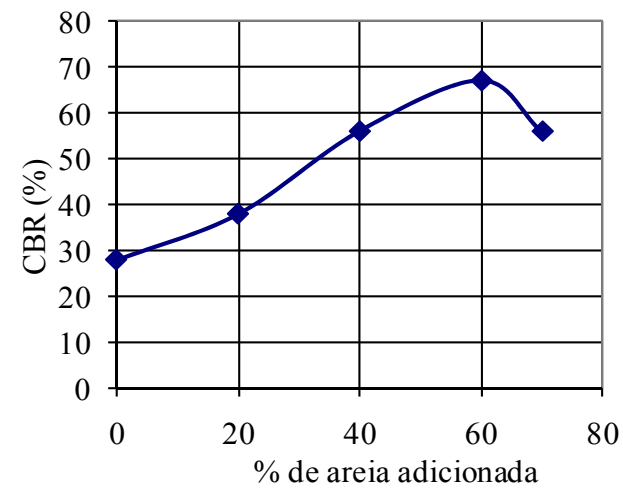

(a) finas - LG' por exemplo - apresentam maior dificuldade para o fluxo de água que solos com partículas mais grossas - LA' por exemplo - o que se traduz em coeficientes de permeabilidade muito baixos para solos argilosos.

\subsection{Ensaio de CBR}

O ensaio de CBR (California Bearing Ratio) e expansão foram executados na energia intermediária com a finalidade de obter os valores desses índices para as misturas solo-areia. A Figura 10a mostra os resultados desses ensaios; nela nota-se um aumento do índice de suporte, a partir do solo natural, em função do aumento do teor de areia adicionada, até a quantidade de $60 \%$, de $28 \%$ para $67 \%$; a partir deste teor de areia o valor do CBR decresce.

A Figura 10b apresenta os valores de expansão obtidos a partir do ensaio de CBR. Nela verifica-se que as expansões são baixas, menores que $0,5 \%$, para todos os teores de areia de fundição adicionado; também nota-se uma tendência decrescente da expansão com o incremento da porcentagem de areia.

\subsection{Ensaio Triaxial Cíclico}

O ensaio triaxial cíclico foi realizado com o propósito de investigar a influência da incorporação da areia de fundição a solos lateríticos argilosos no valor de módulo de resiliência. Foi utilizado o Modelo Composto

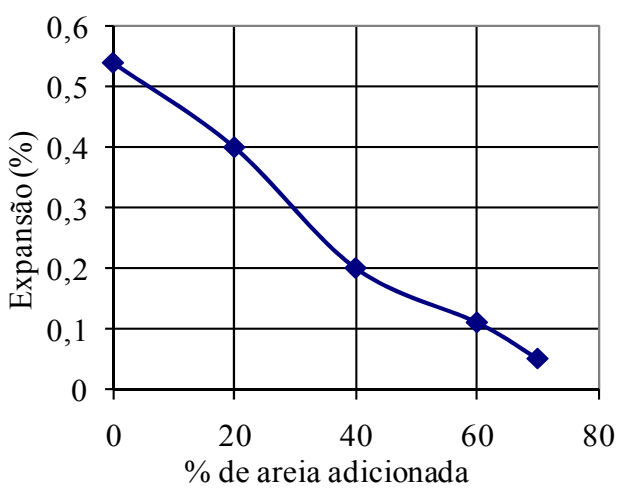

(b)

Figura 10. Variação dos valores de CBR e expansão com o teor de areia de fundição adicionado à matriz Jardim Botânico 
$\left(M_{R}=k_{1} \sigma^{k_{2}} \sigma^{k_{3}}\right)$ como modelo para representação do módulo de resiliência $\left(\mathrm{M}_{\mathrm{R}}\right)$ em função das tensões de confinamento e desvio que atuam no material. Nas Tabelas 4 e 5 são apresentados os modelos obtidos dos ensaios triaxiais cíclicos, com três réplicas para cada teor areia/solo, para os solos do Jardim Botânico e Nova Aliança, respectivamente.

Com o objetivo de estimar os valores de módulos de resiliência das misturas solo-areia apresentariam em um pavimento real, foi simulada uma estrutura de pavimento na qual foram determinadas as tensões atuantes no centro da camada de base através do programa computacional ELSYM5. Considerando que o programa computacional utilizado para a estimativa das tensões é elástico linear, o cálculo foi feito iterativamente, conforme o que segue: foi arbitrado um valor de módulo de resiliência inicial para a camada de base, cujo material apresenta módulo de resiliência dependente do estado de tensões e foram determinadas as tensões atuantes com o auxílio do programa; com essas tensões, foram calculados os valores dos módulos de resiliência dessas camadas utilizando-se os modelos apresentados nas Tabelas 4 e 5; com os novos valores dos módulos foram determinadas as tensões atuantes e, novamente, recalculados os valores dos módulos; esse procedimento foi repetido até a obtenção de valores de módulos de resiliência semelhantes após duas iterações consecutivas. As características iniciais do pavimento simulado foram:

- Revestimento asfáltico, tipo tratamento superficial invertido triplo: espessura de $25 \mathrm{~mm}$; coeficiente de Poisson de 0,35 e $\mathrm{M}_{\mathrm{R}}=1.500 \mathrm{MPa}$;

- Camada de base: espessura de $150 \mathrm{~mm}$; coeficiente de Poisson de 0,40 e $\mathrm{M}_{\mathrm{R}}=200 \mathrm{MPa}$ (inicial);

- Camada de sub-base de solo: espessura de 150 $\mathrm{mm}$; coeficiente de Poisson de 0,40 e $\mathrm{M}_{\mathrm{R}}=100 \mathrm{MPa}$;

- Subleito: coeficiente de Poisson de 0,45 e $M_{R}=$ $50 \mathrm{MPa}$.

Tabela 4. Modelos compostos obtidos dos ensaios triaxiais cíclicos e valores de Módulo de Resiliência calculados a partir desses modelos para a matriz Jardim Botânico

\begin{tabular}{|c|c|c|c|c|c|c|}
\hline Solo & $K_{1}$ & $K_{2}$ & $K_{3}$ & $R^{2}$ & $\begin{array}{c}M_{R 1} \\
(M P a)\end{array}$ & $\begin{array}{c}M_{R 2} \\
(M P a)\end{array}$ \\
\hline \multirow{5}{*}{ JB0AF } & 400,717 & 0,066 & $-0,020$ & 0,92 & 439 & 445 \\
\hline & 548,492 & 0,086 & $-0,099$ & 0,91 & 407 & 413 \\
\hline & 672,353 & 0,051 & $-0,143$ & 0,96 & 353 & 352 \\
\hline & \multicolumn{4}{|c|}{ Média } & 400 & 403 \\
\hline & \multicolumn{4}{|c|}{ Desvio Padrão } & 43 & 47 \\
\hline \multirow{5}{*}{ JB20AF } & 1109,16 & 0,037 & $-0,293$ & 0,97 & 241 & 247 \\
\hline & 948,530 & 0,033 & $-0,231$ & 0,97 & 286 & 279 \\
\hline & 987,922 & 0,010 & $-0,217$ & 0,99 & 299 & 291 \\
\hline & \multicolumn{4}{|c|}{ Média } & 275 & 272 \\
\hline & \multicolumn{4}{|c|}{ Desvio Padrão } & 30 & 23 \\
\hline \multirow{5}{*}{ JB40AF } & 215,155 & 0,444 & $-0,499$ & 0,91 & 87 & 89 \\
\hline & 193,460 & 0,303 & $-0,332$ & 0,91 & 108 & 110 \\
\hline & 253,239 & 0,285 & $-0,348$ & 0,95 & 115 & 118 \\
\hline & \multicolumn{4}{|c|}{ Média } & 103 & 106 \\
\hline & \multicolumn{4}{|c|}{ Desvio Padrão } & 15 & 15 \\
\hline \multirow{5}{*}{ JB60AF } & 75,303 & 0,555 & $-0,320$ & 0,93 & 120 & 137 \\
\hline & 67,038 & 0,574 & $-0,320$ & 0,94 & 117 & 134 \\
\hline & 112,021 & 0,629 & $-0,493$ & 0,95 & 100 & 108 \\
\hline & \multicolumn{4}{|c|}{ Média } & 112 & 126 \\
\hline & \multicolumn{4}{|c|}{ Desvio Padrão } & 11 & 16 \\
\hline \multirow{5}{*}{ JB70AF } & 10,055 & 0,851 & $-0,173$ & 0,97 & 127 & 148 \\
\hline & 7,837 & 0,945 & $-0,224$ & 0,98 & 110 & 132 \\
\hline & 8,961 & 0,877 & $-0,183$ & 0,98 & 122 & 145 \\
\hline & \multicolumn{4}{|c|}{ Média } & 120 & 142 \\
\hline & \multicolumn{4}{|c|}{ Desvio Padrão } & 9 & 9 \\
\hline \multirow{5}{*}{ JB60AV } & 39,67 & 0,72 & $-0,33$ & 0,97 & 116 & 139 \\
\hline & 113,69 & 0,55 & $-0,38$ & 0,97 & 123 & 139 \\
\hline & 109,78 & 0,60 & $-0,42$ & 0,94 & 118 & 135 \\
\hline & \multicolumn{4}{|c|}{ Média } & 119 & 138 \\
\hline & \multicolumn{4}{|c|}{ Desvio Padrão } & 4 & 2 \\
\hline
\end{tabular}


Para a estrutura do pavimento descrita anteriormente foram simulados dois tipos de carregamentos, com a finalidade de permitir a eventual comparação dos resultados obtidos com a utilização do programa ELSYM5 com os oriundos de programas que utilizam elementos finitos axi-simétricos (FEPAVE II, por exemplo) e permitem a consideração de modelos constitutivos mais complexos para os materiais do pavimento, mas demandam, por sua vez, carregamento axi-simétrico. A seguir são apresentadas as duas condições de carregamento consideradas:

- Carregamento duplo: duas cargas circulares de 20,0 KN com pressão de enchimento do pneu de $0,56 \mathrm{MPa}$, afastadas de $300 \mathrm{~mm}$ de centro a centro.

- Carregamento simples: uma carga circular de 40,0 KN com pressão de enchimento do pneu de $0,56 \mathrm{MPa}$;

Assim, para as duas condições de carregamento consideradas, foram obtidos dois valores de $\mathrm{M}_{R}$, a saber:

- $\mathrm{M}_{\mathrm{R} 1}$, calculado a partir das tensões atuantes no ponto médio da base quando aplicado carregamento duplo;

- $\mathrm{M}_{\mathrm{R} 2}$, calculado a partir das tensões atuantes no ponto médio da base quando aplicado carregamento simples.

A Tabela 4, além de apresentar os modelos compostos obtidos dos ensaios triaxiais cíclicos para o solo Jardim Botânico e suas composições com areia de fundição e areia virgem, também apresenta as estimativas dos valores dos módulos de resiliência desses materiais obtidas a partir da simulação da estrutura de pavimento e condições anteriormente descritas. Observando-se essa tabela pode-se afirmar que os valores dos módulos de resiliência obtidos para os dois carregamentos arbitrados são bastante semelhantes, com tendência de valores maiores para o carregamento simples.

A Tabela 5 apresenta os modelos compostos obtidos para o solo Nova Aliança (NV) e suas composições com areia de fundição, além das estimativas dos valores dos módulos de resiliência desses materiais obtidas da simulação da estrutura de pavimento e condições descritas anteriormente.

A Figura 11 apresenta as faixas de variação dos valores dos Módulos de Resiliência para as simulações com carregamento duplo $\left(\mathrm{a}, \mathrm{M}_{\mathrm{R} 1}\right)$ e carregamento simples $\left(b, M_{R 2}\right)$, respectivamente, em função do teor de areia de fundição adicionado à matriz de solo Jardim Botânico. As faixas de variação dos valores dos módulos de resiliência foram estabelecidas a partir dos valores máximo e mínimo apresentados na Tabela 4.

Observando-se a Figura 11 nota-se que o valor do módulo de resiliência diminuiu de, aproximadamente, $400 \mathrm{MPa}$, para o solo Jardim Botânico puro, até um valor da ordem de $100 \mathrm{MPa}$ para $40 \%$ de areia adicionada, oscilando em torno desse valor para os demais teores crescentes de areia adicionada.

Bernucci (1995) e Alvarez Neto (1998) pesquisaram a utilização do solo arenoso fino laterítico (SAFL) em pavimentos de baixo volume de tráfego e apresentaram valores de módulos de resiliência obtidos por meio de retroanálise de bacias de deflexão obtidas em rodovias construídas com bases de SAFL no Estado de São Paulo. Esses estudos mostram que as bases de solos arenosos finos lateríticos apresentam, em serviço, módulo de resiliência variando entre $150 \mathrm{e}$ $300 \mathrm{MPa}$. Por outro lado, Villibor (1981) relata que as camadas de bases construídas com SAFL apresentam

Tabela 5. Modelos compostos obtidos dos ensaios triaxiais cíclicos e valores de Módulo de Resiliência calculados a partir desses modelos para a matriz Nova Aliança

\begin{tabular}{|c|c|c|c|c|c|c|}
\hline Solo & $K_{1}$ & $K_{2}$ & $K_{3}$ & $R^{2}$ & $\begin{array}{c}M_{R 1} \\
(M P a)\end{array}$ & $\begin{array}{c}M_{R 2} \\
(M P a)\end{array}$ \\
\hline \multirow{5}{*}{ NVOAF } & 651,876 & 0,021 & $-0,107$ & 0,97 & 380 & 377 \\
\hline & 656,258 & 0,019 & $-0,100$ & 0,84 & 394 & 391 \\
\hline & 919,196 & 0,042 & $-0,188$ & 0,88 & 362 & 358 \\
\hline & \multicolumn{4}{|c|}{ Média } & 379 & 375 \\
\hline & \multicolumn{4}{|c|}{ Desvio Padrão } & 16 & 17 \\
\hline \multirow{5}{*}{ NV60AF } & 36,642 & 0,762 & $-0,352$ & 0,97 & 115 & 138 \\
\hline & 23,724 & 0,735 & $-0,230$ & 0,96 & 133 & 150 \\
\hline & 21,333 & 0,766 & $-0,256$ & 0,97 & 116 & 141 \\
\hline & \multicolumn{4}{|c|}{ Média } & 121 & 143 \\
\hline & \multicolumn{4}{|c|}{ Desvio Padrão } & 10 & 6 \\
\hline \multirow{5}{*}{ NV60AV } & 44,864 & 0,660 & $-0,291$ & 0,96 & 121 & 146 \\
\hline & 33,131 & 0,673 & $-0,262$ & 0,98 & 118 & 140 \\
\hline & 34,719 & 0,786 & $-0,351$ & 0,97 & 124 & 143 \\
\hline & \multicolumn{4}{|c|}{ Média } & 121 & 143 \\
\hline & \multicolumn{4}{|c|}{ Desvio Padrão } & 3 & 3 \\
\hline
\end{tabular}




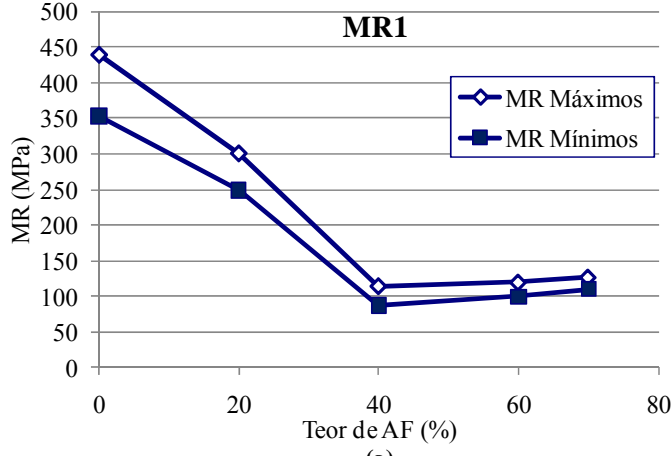

(a)

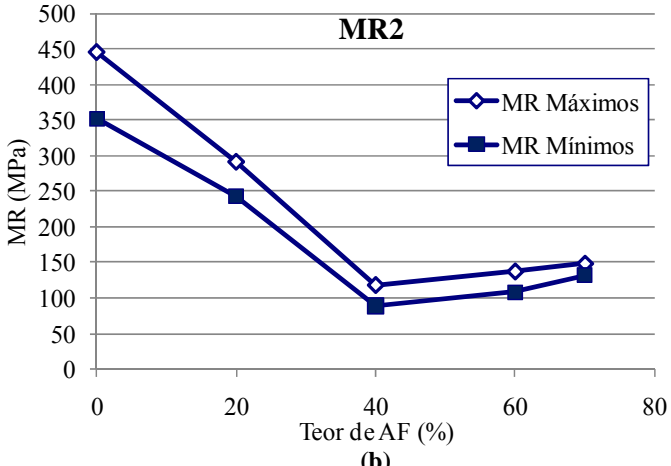

(b)

Figura 11. Faixas de valores dos Módulos de Resiliência para (a) carregamento duplo e (b) simples, em função do teor de areia de fundição adicionado à matriz de solo Jardim Botânico

teores de umidade de equilíbrio abaixo da umidade ótima obtida em laboratório, mesmo em períodos de chuva e, segundo Takeda (2006), essa secagem até alcançar a umidade de equilíbrio pode significar um aumento do valor do módulo de resiliência do material, aproximando-o ou até ultrapassando os valores obtidos em campo.

\subsection{Ensaios Ambientais}

Finalmente foram executados ensaios de adequação ambiental das misturas - Massa Bruta, Lixiviação e Solubilização - com o propósito de determinar a periculosidade do "resíduo" areia de fundição adicionado a solos argilosos e sua possível reutilização em bases e sub-bases de pavimentos de baixo volume de tráfego. Estes ensaios foram executados em três amostras: a) Areia de Fundição; b) Solo Jardim Botânico e c) Mistura do solo Jardim Botânico e Areia de Fundição $(52 \%)$.

Nos ensaios de Lixiviação (NBR 10005:2004 Anexo F) e de Massa Bruta (NBR 10004:2004), a Areia de Fundição apresentou parâmetros dentro dos limites permitidos; já no ensaio de Solubilização, a amostra excedeu os limites permitidos pela
10006:2004 - Anexo G, conforme pode ser observado na Tabela 6. Em função dos resultados desses ensaios, a amostra de Areia de Fundição foi classificada como Classe II A - Resíduo Não Inerte.

O Solo Jardim Botânico apresentou resultados satisfatórios no ensaio de Massa Bruta, quando comparados com os Valores Máximos Permitidos pela NBR 10004:2004. No Ensaio de Lixiviação os valores obtidos satisfazem os limites permitidos pela NBR 10004:2004 - Anexo F. Já no ensaio de Solubilização o Índice de Fenóis ultrapassou os Valores Máximos Permitidos pela NBR 10004:2004 - Anexo G, como pode ser observado na Tabela 7. A partir dos resultados desses ensaios, o solo Jardim Botânico foi classificado como Classe II A - Resíduo Não Inerte.

A mistura do solo Jardim Botânico com a Areia de Fundição (52\%) apresentou parâmetros que satisfazem os limites permitidos pelos ensaios de Lixiviação e de Massa Bruta, mas no ensaio de Solubilização essa mistura também apresentou valores que excedem os limites permitidos pela norma 10004:2004 - Anexo G, como pode ser observado na Tabela 8 . A partir desses resultados, a mistura também foi classificada como Classe II A - Resíduo Não Inerte.

Tabela 6. Resultados parciais do ensaio de Solubilização para a Areia de Fundição

\begin{tabular}{lcccc}
\hline \multicolumn{1}{c}{ Parâmetros } & Unidade & $\boldsymbol{L Q}^{*}$ & $\begin{array}{l}\text { Resultados } \\
\text { Analíticos }\end{array}$ & ABNT NBR 10004:2004 VMP** \\
\hline Índice de Fenóis & $\mathrm{mg} / \mathrm{L}$ & 0,002 & 0,0600 & 0,01 \\
\hline Manganês & $\mathrm{mg} / \mathrm{L}$ & 0,010 & 0,0114 & 0,10 \\
\hline LQ* Limite de Quantificação & \multicolumn{2}{c}{ VMP** Valor Máximo Permitido pela Norma ABNT NBR 10004:2004 } \\
\multicolumn{2}{c}{ Tabela 7. Resultados parciais do ensaio de Solubilização para o solo Jardim Botânico } \\
\hline Parâmetros & Unidade & $\mathbf{L Q *}$ & $\begin{array}{l}\text { Resultados } \\
\text { Analíticos }\end{array}$ & ABNT NBR 10004:2004 VMP** \\
\hline Índice de Fenóis & $\mathrm{mg} / \mathrm{L}$ & 0,002 & 0,04 & 0,01 \\
\hline
\end{tabular}

Tabela 8. Resultados do ensaio de Solubilização para a mistura do solo Jardim Botânico e $52 \%$ de Areia de Fundição

\begin{tabular}{ccccc}
\hline Parâmetros & Unidade & LQ* & $\begin{array}{c}\text { Resultados } \\
\text { Analíticos }\end{array}$ & ABNT NBR 10004:2004 VMP** \\
\hline Índice de Fenóis & $\mathrm{mg} / \mathrm{L}$ & 0,002 & 0,02 & 0,01 \\
\hline
\end{tabular}


Em agosto de 2007, a Companhia de Tecnologia de Saneamento Ambiental, CETESB, publicou a "Decisão de Diretoria N $N^{0} 152 / 2007 / C / E$ que trata da reutilização da areia de fundição. Segundo este documento, a avaliação de propostas de reutilização do resíduo areia de fundição está condicionada a ele ser classificado como Classe II - A ou II - B, de acordo com a norma NBR 10004:2004. Considerando essa decisão, a areia de fundição utilizada nesta pesquisa, misturada a solos argilosos, satisfaz as exigências e poderia ser reaproveitada em bases e sub-bases de pavimentos flexíveis de baixo volume de tráfego, desde que a proposta seja analisada e aprovada pela CETESB.

\section{CONCLUSÕES}

A partir dos resultados apresentados nessa pesquisa pode-se concluir que misturas compostas de $60 \%$ de areia de fundição e $40 \%$ de solos argilosos da região de Sertãozinho-SP, ou mesmo aquelas com $70 \%$ de areia e $30 \%$ de solo poderiam ser utilizadas como material para construção de bases e sub-bases de pavimentos de baixo volume de tráfego, uma vez que elas atendem às exigências estabelecidas na especificação ET-DE-P00-015A do DER-SP (2005), Sub-Base ou Base de Solo Arenoso Fino de Comportamento Laterítico - SAFL.

Do ponto de vista de valores de módulo de resiliência, os resultados de laboratório, obtidos em corposde-prova compactados na umidade ótima e massa específica seca máxima, para as misturas com $60 \%$ e $70 \%$ de areia de fundição, indicaram valores próximos dos alcançados por outros autores a partir de retroanálise de bacias de deflexão de pavimentos em serviço com bases de SAFL. Deve-se destacar que as bases de SAFL secam após a construção e apresentam, no campo, umidades de equilíbrio bastante inferiores à ótima, o que, certamente, leva a um aumento nos valores de seus módulos de resiliência.

Além disso, os resultados dos ensaios de CBR das misturas com $60 \%$ de areia de fundição sugerem que elas poderiam ser utilizadas como material para base de pavimentos de tráfego leve $\left(\mathrm{N} \leq 5 \times 10^{6}\right.$ solicitações de eixo padrão) segundo o Manual de Pavimentação do DNIT (2006).

A título de exemplo, a utilização de areia de fundição na construção de uma base com $15,0 \mathrm{~cm}$ de espessura, nas proporções apresentadas nesse estudo, consumiria $0,18 \mathrm{t}$ de resíduo por metro quadrado de base e, para uma rodovia vicinal de 6,0 m de largura, o reaproveitamento alcançaria, aproximadamente, $1,1 \mathrm{t}$ de areia por metro linear, ou ainda, $1100 \mathrm{t}$ de areia por quilômetro de rodovia.

Portanto, constata-se que o reuso da Areia de Fundição é promissor como material de construção de camadas de pavimentos, o que, certamente, favoreceria o meio ambiente de várias maneiras: evitando-se a disposição inadequada desse resíduo em aterros; evitando-se a exploração desnecessária de recursos naturais adicionais, além de permitir a utilização de materiais argilosos locais onde há escassez de solos arenosos.

Entretanto, deve-se alertar que o emprego dessas misturas areia de fundição e solos argilosos em pavimentos está sujeito à apreciação e aprovação dos organismos ambientais uma vez que, à luz dos ensaios ambientais, são classificadas como resíduo Classe II$\mathrm{A}$, não perigoso e não inerte.

\section{REFERÊNCIAS BIBLIOGRÁFICAS}

ABIFA, Associação Brasileira de Fundição (2009). http://www.abifa.com.br

Alvarez Neto, L. (1998). Proposta de um método de dimensionamento de pavimentos flexíveis para vias de baixo volume de tráfego com a utilização de solos lateríticos. Tese (Doutorado) - Escola Politécnica - Universidade de São Paulo. São Paulo

Associação Brasileira de Normas Técnicas (2004). NBR 10004:2004: Resíduos Sólidos. Rio de Janeiro.

Berndt, H. (1989). Processo Shell: materiais e tecnologia. Tradução de Herbert Schwarz e outros. ABIFA - Associação Brasileira de Fundição. São Paulo.

Bernucci, L.L.B. (1995). Considerações sobre o dimensionamento de pavimentos utilizando solos lateríticos para rodovias de baixo volume de tráfego. Tese (Doutorado) - Escola Politécnica - Universidade de São Paulo. São Paulo.

DER-SP (2005). Especificações Técnicas - Pavimentação. ET-DE-P00015A, Sub-base ou Base de Solo Arenoso Fino de Comportamento Laterítico - SAFL. Departamento de Estradas de Rodagem, São Paulo.

DNIT (2006). Manual de Pavimentação. Publicação IPR-179. Departamento Nacional de Infra-estruturas de Transportes, Rio de Janeiro.

Mariotto, C.L. (2000). Regeneração de areias de Fundição. Seminário Nacional sobre Reuso/Reciclagem de resíduos sólidos industriais SMA/SP.

McIntyre, S.W. et al. (1992). Beneficiation and Reuse of Foundry Sand Residuals: A Preliminary Report. Transactions of the American Foundry men's Society, vol. 100, p.201-208.

Nogami, J.S.; Villibor, D.F. (1995). Pavimentação de baixo custo com solos lateríticos. São Paulo.

Siegel, M. et al. (1982). Fundição. Notas de Aulas. ABM - Associação Brasileira de Metais. 13 ${ }^{\mathrm{a}}$ ed. São Paulo: Édile Serviços Gráficos e Editora Ltda.

Takeda, M.C. de. (2006). A influência da variação da umidade póscompactação no comportamento mecânico de solos de rodovias do interior paulista. Dissertação (Mestrado) - Escola de Engenharia de São Carlos - Universidade de São Paulo - São Paulo.

Villibor, D.F. (1981). Pavimentos Econômicos, novas considerações. Tese (Doutorado) - Escola de Engenharia de São Carlos - Universidade de São Paulo - São Paulo.

Villibor, D.F.; Nogami, J.S.; Cincerre, J.R.; Serra, P.R.M.; Zuppolini, A.N.; (2007). Pavimentos de Baixo Custo para Vias Urbanas, bases alternativas com solos lateríticos. São Paulo. 